\title{
A Multifaceted Approach to Supporting Mothers of Premature Infants
}

\author{
Parisa Mohagheghi \\ Iran University of Medical Sciences
}

Afsaneh Keramat

Shahroud University of Medical Sciences

Reza Chaman

Shiraz University of Medical Sciences

Ahmad Khosravi

Shahroud University of Medical Sciences

Seyed Abbas Mousavi

Mazandaran University of Medical Sciences

Seyedeh Saeedeh Mousavi ( $\nabla$ saideh.musavi@yahoo.com )

Iran University of Medical Sciences

\section{Research Article}

Keywords: Infant, Premature, mothers, health planning support

Posted Date: April 30th, 2021

DOl: https://doi.org/10.21203/rs.3.rs-379321/v1

License: (1) (1) This work is licensed under a Creative Commons Attribution 4.0 International License. Read Full License 


\section{Abstract \\ Background}

Premature birth exposes mothers to a strange experience for which they are not mentally ready. Premature birth exposes mothers to a strange experience for which they are not mentally ready. This study aimed to examine the effect of a multi-faceted supportive approach on the levels of perceived support in mothers.

\section{Methods}

The present experimental study was conducted on 143 mothers with preterm infants, (In the intervention group, 75 infants and mothers and 68 infants and mothers in the control group), in the NICUs of two educational and referral hospitals of Tehran, Iran; from Feb 14, 2016 to May 14, 2016. The inclusion criteria were: having a preterm infant with gestational age $<37$ weeks, birth weight $<2500 \mathrm{gr}$, high probability of survival, Iranian nationality and ability to communicate verbally. Exclusion criteria were: preterm infants without abnormality or disabling conditions such as intra ventricular hemorrhage (IVH) grade 3 or 4 . The designed intervention was conducted based on the support system pattern of mothers with premature infants. Different interventions in support (appraisal, instrumental, emotional, and informational support) of mothers in NICU were planned for the supportive program, which was gradually implemented within 3 months of the intervention. The Nurse Parent Support Tool (NPST) was used to assess the mothers' perceptions of the perceived support. The control group received routine care. The obtained data were analyzed by STATA software 13. Classified variables were analyzed using t-test, chi-square and Inverse Probability Treatment Weights (IPTW).

\section{Results}

After adjusted mean differences ( $95 \%$ confidence interval) of outcomes between two groups, results showed that the all support scores including total support, -1.83 (95\% Cl -1.6 to -2.06), Instrumental support, -1.23 (95\% $\mathrm{Cl}-1.04$ to -1.43 ), Emotional support, -1.87 (95\% Cl -2.15 to 1.6 ) and Appraisal support, -2.01 (95\% $\mathrm{Cl}-1.73$ to $-2.29)$, and Informational support, $-2.12(95 \% \mathrm{Cl}-1.82$ to -2.43$)$, in the experimental group were significantly higher than in the control group $(\mathrm{P}<0.001)$.

\section{Conclusions}

The information, support and early intervention play important roles in the maternal empowerment to cope with her situation.

\section{Introduction}

Premature birth and the infant admission in the Neonatal intensive care unit (NICU) exposes mothers to a strange and stressful experience for which they are not mentally ready. Many mothers have symptoms of depression, anxiety, and Post Traumatic Stress Disorder (PTSD) (1). 
Some mothers may want to share experiences with others, but they avoid it because of feelings of social isolation, guilt, shame, and the thought that others do not understand (2).

Mothers' perceptions of the amount of emotional support can predict their stress level (3), and mothers' support is not only important for their mental health, but also has potential achievements to improve the quality of mother-infant interactions and the child's subsequent growth (4).

Supporting mothers of premature infants is also important for public health because the costs associated with mental health problems are estimated as the largest source of the global economic burden of noncommunicable diseases (5).

Many interventional programs have been developed and evaluated for premature infants' mothers. Most of them focus on boosting the infants' nervous development, but some of them focus on improving maternal outcomes such as maternal behavior, mother-infant interaction, or mothers' health and coping skills. Many programs include education of mothers on various infant-related topics (e.g. developmental care, and maternal care practices in the NICU) or mother-related topics (e.g. communication and coping skills and promoting mother-infant communication). Interventional programs focus on a variety of topics, including developmental care, stress reduction, discharge planning, and breastfeeding support. There is great evidence that the one by one training, which focuses on the mother-infant relationship and maternal participation in infant care such as COPE (creating opportunities for parent empowerment), NIDCAP (Newborn Individualized Developmental Care and Assessment Program), and MITP (mother-infant transaction program), can reduce the mothers' stress in the NICU, and also the COPE reduces the mothers' depression (6). However, many of these interventions have been started after discharge or a few days after the infants' admission to NICU, and the mothers were left helpless in the first days of birth, especially in the first encounter with the infants.

Findings indicate that support systems do not always support mothers emotionally or practically at the bedside in a timely or helpful manner $(3,7-10)$ and this can put more stress on family engagement patterns, especially in cases where mothers are not ready for premature birth $(9,11)$.

Interventions and changes in care and policies should be evidence-based and based on the mothers' needs and preferences; hence, there is a need for evaluation of attractive, acceptable, and practical interventions in neonatal units that support mothers in different ways.

Efforts have been made to develop interdisciplinary guidelines to support mothers of infants in the NICU. The National Perinatal Association established a multidisciplinary committee in 2015 (consisting of professionals and mothers of hospitalized infants) to prepare a guideline. Finally, a multifaceted approach was proposed to support mothers, including both the maternal-specific interventions (e.g. mental health support, mental education, and peer-to-peer support) and broad concentrated approaches at hospitals (e.g. family-centered care). The guidelines generally recognize that there are weak evidences supporting these recommendations and there are a need for further researches to identify the most effective interventions, benefits, or their harms to patients, families, and staff (12).

The present study had a multi-faceted approach and widely investigated the needs of mothers of preterm infants in the world, especially Iran $(11,13)$ and studied supportive interventions for mothers of premature 
infants and designed a model in this regard (14) based on the evidence and available possibilities, and also designed a supportive and multi-faceted intervention that has been started before the first exposure of mothers with the infants. In the research, we sought to measure the consequences of its implementation on the levels of perceived support in mothers in different dimensions and take steps to develop clinical guidelines to provide comprehensive support for helpless mothers of premature infants.

\section{Methods}

This research was approved by the Ethics Committee of Shahroud University of Medical Sciences (code: 930/24). This experimental study was conducted in NICUs of two hospitals of Tehran; Mahdieh and Shahid Akbar-Abadi, from Feb 14, 2016 to May 14, 2016. Both are educational and referral centers including three levels of NICU. Unit of random allocation was hospitals. Avoiding the contamination between parents is the reason of this type of randomization. In the long run Mahdieh assigned to intervention site and Shahid AkbarAbadi assigned as control site. The study population of this study was the mothers of premature newborns. The Sampling was done after obtaining written consent.

All premature newborns and their mothers with inclusion/exclusion criteria were recruited in the study during three months period (15). The inclusion criteria were: having a preterm infant with gestational age $<37$ weeks, birth weight $<2500 \mathrm{gr}$, High probability of survival, Declaration of consent to participate in the study, Iranian nationality and ability to communicate verbally. Exclusion criteria were: preterm infants without abnormality or disabling conditions such as intraventricular hemorrhage (IVH) grade 3 or 4.

In the intervention group, 75 infants and mothers were included and 68 infants and mothers were included in the control group during the study period.

Intervention: The designed intervention was conducted based on the support system pattern of mothers with premature infants in the experimental group. In this pattern, parents and babies are at the center of the supportive model that need to be supported at critical transitional periods and consisted of preconception, prenatal, neonatal unit, the transition to home, and at home. Different interventions in support of mothers in $\mathrm{NICU}$ were planned for the program, which was gradually implemented within 3 months of the intervention. At the first stage, mothers were prepared for the first visit of their infants in the neonatal ward as described in another paper. At the same time, the mothers were encouraged to a constant presence in the NICU to gradually become empowered in the maternal process by the constant presence in the ward, observation, and guided participation in the care of the infants (appraisal and Instrumental support). The researcher, who also had the experience of having a premature baby, was present in the NICU six days a week from 9 am to $4 \mathrm{pm}$ and contacted the neonatologist and nurses for the infants to inform about details of the infants' conditions, and then conveyed the appropriate information to the mothers with simple and fluent words. Furthermore, the information about the NICU, appearance, and behavior of preterm infants, and the way of maternal roles were provided for every mother according to their understanding, literacy, and needs, and responded to any questions and, if necessary, repeated the training (informational support). The researcher examined the mother's relationship with the infants, and accordingly, guided the mothers to interact with the infants, and identify their behavioral symptoms (appraisal support). She guided the mothers to carry out baby calming interactions through the exchange of smell (encouraging the mother to put milk pad under the infant's head and picking up 
the previous pad to keep it on her side during milking and for the separation times from the baby), touch slow and steady, quiet whispering and eye contact with the baby (emotional support). She provided breastfeeding training in the neonatal ward in counseling and practical assistance, and followed up by phone (informational support) after the baby was discharged., She was provided encouragement, practical assistance, training, counseling for the mothers by various ways to start kangaroo care and perform it as soon as possible (appraisal and instrumental support). In cases of intra-ward or inter-ward transfer of the infants, she accompanied the mothers and explained the new conditions to the mothers (informational support). The mothers became members of the "MATIN mothers" group in the social network to express their concerns in that space (emotional support) and gain practical information by talking to mothers who had experienced having premature infants. In the group, which was under the constant supervision of the researcher, there were new mothers and mothers who had successful experience of having premature infants in previous years. In the group, the researcher uploaded different educational contents about breastfeeding, kangaroo care, massage, infant follow-up, etc. according to the mothers' needs, and answered possible uploaded questions, and monitored mothers' interactions to prevent any misguided guidance and advice (informational support).

A session was held often once a week with the researcher as a leader/facilitator in the mothers' restroom by inviting an experienced volunteer mother who had previously been trained about supportive boundaries in a four-hour workshop. In the session, the mothers' needs and demands were discussed and the practical experiences of the peer mother were used (informational and appraisal support).

An attempt was made to provide spiritual support for mothers by emphasizing trust, recourse, patience, and submission to divine destiny. The telephone number was provided for mothers who could call and ask any questions they might have throughout the day, whether during hospitalization or discharge, up to three months after the infant's birth (informational support). Before discharge, the mothers were taught about checking the temperature, method of bathe, giving the baby possible medications, etc. (appraisal support) and the way of pursuing recommended follow-ups for the premature infant, including vision, hearing and etc. and they were reminded until three months after birth (informational support).

Measurements: Data collection tools included: demographic questionnaire and maternal and infant clinical data, the Nurse Parent Support Tool (NPST). Demographic questionnaire including: mother's age, mother's education level, mother's employment status, insurance status, family income, ethnicity and mother's clinical data including: parity, abortion, live child, multiple pregnancy status, type of delivery and neonatal clinical data included: sex of infant, gestational age, birth weight, number of days of invasive and non-invasive ventilation.

We utilized the Nurse Parent Support Tool (NPST) to assess the mother's perception of the perceived support in the four fields, instrumental, emotional, appraisal, and informational support. The Miles Questionnaire (1998) is a 21-item self-report tool that assesses the mother's perception of perceived support in four fields: instrumental, emotional, appraisal, and informational. Answers are ranked on a Likert scale. A score 1 means the minimum support and 5 means the maximum support. The validity and reliability of the English and Persian versions of the questionnaire have already been determined $(16,17)$.

Statistical Analysis: The obtained data were analyzed by Stata 13 (StataCorp, College Station, Texas). T-test used for comparison of means between the two groups and chi-square test was used to assess the independence between categorical variables. For control of pre-treatment variable due to cluster randomization 
(not random allocation at the individual level), we used Inverse Probability Treatment Weights (IPTW) to compute weighted averages of the outcomes for each intervention level (18). The IPTW method was utilized to control the heterogeneity in basic variables between two groups. In this regard, variable entitled disease intensity was initially generated based on the infant's requirements and a lack of need for invasive and noninvasive ventilation. Then, the treatment variable was modelled by logistic regression on basic variables of infant's disease intensity, age, birth weight, the reception-time status of anxiety and reception-time personality anxiety which is known as the propensity score (PS). The weights are 1/PS for the intervention group participants and 1/ (1-PS) for the control participants. The average treatment effect (ATE) is an adjusted estimate of difference scores between two groups using weights.

\section{Results}

Table 1 show mothers' baseline characteristics. Since the patients were not divided randomly rather the hospitals were randomly allocated to intervention and control group, both the control and experiment groups were significantly different in terms of some demographic (education, occupation, insurance status and mother ethnicity) and clinical factors (birth age, birth weight and number of non-invasive ventilation days) (Table 1).

Table 1. A comparison of demographic information and clinical data between the two intervention and control groups 


\begin{tabular}{|c|c|c|c|}
\hline \multirow[t]{2}{*}{ Variables } & Control & Intervention & \multirow[t]{2}{*}{$P$ value } \\
\hline & $N=68$ & $\mathrm{~N}=75$ & \\
\hline \multicolumn{4}{|l|}{ Mother's education (\%) } \\
\hline Under diploma & $24(35.3)$ & $15(20.0)$ & 0.01 \\
\hline Diploma & $35(51.5)$ & $36(48.0)$ & \\
\hline Academic & $9(13.2)$ & $24(32.0)$ & \\
\hline \multicolumn{4}{|l|}{ Mother's employment (\%) } \\
\hline Household & $65(95.6)$ & $64(85.3)$ & 0.05 \\
\hline Employed & $3(4.4)$ & $11(14.7)$ & \\
\hline \multicolumn{4}{|l|}{ Status of insurance } \\
\hline Social insurance or treatment services & $39(57.4)$ & $33(44)$ & 0.03 \\
\hline Rural or health insurance & $25(36.8)$ & $26(34.7)$ & \\
\hline Complementary insurance & $4(5.9)$ & $16(21.3)$ & \\
\hline \multicolumn{4}{|l|}{ Mother's ethnicity (\%) } \\
\hline Persian & $8(11.8)$ & $36(48.0)$ & $<0.001$ \\
\hline Non-Persian & $60(88.2)$ & $39(52.0)$ & \\
\hline \multicolumn{4}{|l|}{ Parity (\%) } \\
\hline 1 & $35(51.5)$ & $51(68.0)$ & 0.13 \\
\hline 2 & $24(35.3)$ & $20(26.7)$ & \\
\hline$\geq 3$ & $9(13.2)$ & $4(5.3)$ & \\
\hline \multicolumn{4}{|l|}{ Abortion (\%) } \\
\hline 0 & $53(77.9)$ & $59(78.7)$ & 0.72 \\
\hline 1 & $11(16.0)$ & $9(12.0)$ & \\
\hline 2 & $3(4.0)$ & $4(5.3)$ & \\
\hline 3 & $1(1.5)$ & $3(4.0)$ & \\
\hline \multicolumn{4}{|l|}{ alive children (\%) } \\
\hline 1 & $21(30.9)$ & $26(34.7)$ & 0.15 \\
\hline 2 & $31(45.0)$ & $39(52.0)$ & \\
\hline 3 & $12(17.6)$ & $10(13.3)$ & \\
\hline 4 & $4(5.9)$ & $0(0.0)$ & \\
\hline
\end{tabular}

Pregnancy status in terms of multiple birth (\%) 


\begin{tabular}{|c|c|c|c|}
\hline Single & $42(61.8)$ & $40(53.3)$ & 0.053 \\
\hline Twin & $26(38.2)$ & $29(38.7)$ & \\
\hline Triplet & $0(0.0)$ & $6(8.0)$ & \\
\hline \multicolumn{4}{|l|}{ Type of delivery (\%) } \\
\hline Natural & $13(19.1)$ & $10(13.3)$ & 0.26 \\
\hline Caesarean & $55(80.9)$ & $65(86.70)$ & \\
\hline \multicolumn{4}{|l|}{ sex of infant (\%) } \\
\hline Male & $34(50.0)$ & $35(46.7)$ & 0.69 \\
\hline Female & $34(50.0)$ & $40(53.3)$ & \\
\hline Family income (\$) (Mean \pm SD) & $341.5 \pm 138.7$ & $400 / 2 \pm 312 / 2$ & 0.08 \\
\hline Mother's age (Mean $\pm S D)$ & $28.3 \pm 5.8$ & $28.5 \pm 5.4$ & 0.84 \\
\hline Birth age (Mean $\pm S D)$ & $32.3 \pm 2.1$ & $30.9 \pm 2.6$ & $<0.001$ \\
\hline Birth weight $(\mathrm{Kg})($ Mean $\pm S D)$ & $1.7 \pm 0.4$ & $1.5 \pm 0.48$ & $<0.001$ \\
\hline $\begin{array}{l}\text { Number of invasive ventilation days } \\
\text { (Mean } \pm S D \text { ) }\end{array}$ & $0.7 \pm 3.1$ & $2.4 \pm 10.4$ & 0.09 \\
\hline Number of non-invasive ventilation days (Mean \pm SD) & $0.8 \pm 3.5$ & $2.4 \pm 3.8$ & 0.01 \\
\hline
\end{tabular}

Adjusted mean differences (95\% confidence interval) of outcomes between two groups are depicted in table 2 . Results of this study showed that the all of the support scores including 1-total -1.83 (95\% Cl -1.6 to -2.06), 2Instrumental support -1.23 (95\% Cl-1.04 to -1.43), 3- Emotional support -1.87 ( $95 \% \mathrm{Cl}-2.15$ to 1.6$)$ and 4 Appraisal support -2.01 (95\% Cl-1.73 to -2.29), and 5-Informational support -2.12 (95\% Cl-1.82 to -2.43), in the experimental group were significantly higher than in the control group $(P<0.001)$.

Table 2. The average score of Perceived support between the two intervention and control groups 


\begin{tabular}{|llllllll|}
\hline $\begin{array}{l}\text { Perceived } \\
\text { support }\end{array}$ & $\begin{array}{l}\text { Intervention } \\
\text { (before } \\
\text { adjustment) }\end{array}$ & $\begin{array}{l}\text { Control } \\
\text { (before } \\
\text { adjustment) }\end{array}$ & $\begin{array}{l}\text { Intervention } \\
\text { (SE) }\end{array}$ & $\begin{array}{l}\text { Control } \\
\text { (SE) }\end{array}$ & $\begin{array}{l}\text { *Average } \\
\text { treatment } \\
\text { effect } \\
\text { (SE) }\end{array}$ & $\begin{array}{l}95 \% \mathrm{Cl} \\
\text { for } \\
\text { difference }\end{array}$ & $\begin{array}{l}P \\
\text { value }\end{array}$ \\
\hline Total support & $4.49 \pm 0.44$ & $2.42 \pm 0.76$ & $4 / 49(0 / 05)$ & $\begin{array}{l}2 / 66 \\
(0 / 10)\end{array}$ & $\begin{array}{l}1.83 \\
(0 / 12)\end{array}$ & $\begin{array}{l}1.6 \text { to } \\
2.06\end{array}$ & $<0.001$ \\
\hline $\begin{array}{l}\text { Instrumental } \\
\text { support }\end{array}$ & $4.6 \pm 0.44$ & $3.25 \pm 0.68$ & $4 / 61(0 / 05)$ & $\begin{array}{l}3 / 38 \\
(0 / 08)\end{array}$ & $\begin{array}{l}1.23 \\
(0 / 10)\end{array}$ & $\begin{array}{l}1.04 \text { to } \\
1.42\end{array}$ & $<0.001$ \\
\hline $\begin{array}{l}\text { Emotional } \\
\text { support }\end{array}$ & $4.55 \pm 0.41$ & $2.41 \pm 0.94$ & $4 / 55(0 / 05)$ & $\begin{array}{l}2 / 67 \\
(0 / 13)\end{array}$ & $\begin{array}{l}1.87 \\
(0 / 14)\end{array}$ & $\begin{array}{l}2.15 \text { to } \\
1.60\end{array}$ & $<0.001$ \\
\hline $\begin{array}{l}\text { Appraisal } \\
\text { support }\end{array}$ & $4.57 \pm 0.06$ & $2.34 \pm 1.08$ & $4 / 56(0 / 06)$ & $\begin{array}{l}2 / 54 \\
(0 / 13)\end{array}$ & $\begin{array}{l}2.01 \\
(0 / 14)\end{array}$ & $\begin{array}{l}1.73 \text { to } \\
2.29\end{array}$ & $<0.001$ \\
\hline $\begin{array}{l}\text { Informational } \\
\text { support }\end{array}$ & $4.33 \pm 0.61$ & $1.94 \pm 0.83$ & $4 / 33(0 / 07)$ & $\begin{array}{l}2 / 21 \\
(0 / 14)\end{array}$ & $\begin{array}{l}2.12 \\
(0 / 16)\end{array}$ & $\begin{array}{l}1.82 \text { to } \\
2.43\end{array}$ & $<0.001$ \\
\hline
\end{tabular}

* ATE is adjusted for infant's disease intensity, birth age, birth weight, reception status anxiety and reception trait anxiety using the IPTW method.

\section{Discussion}

Overlapping the needs of mothers of premature infants has made it difficult to determine what kind of help is most helpful; hence, it is more helpful for professionals to cover a wide range of needs by providing multidimensional support.

The idea of maternal satisfaction can be achieved by focusing on fulfilling the mothers' specific needs just through mother-to-mother and professional-to-mother support programs so that our intervention could have a positive impact on the maternal perceived sense of support in different fields of informational, emotional, instrumental, and appraisal support.

Researchers have found significant differences in needs, response to needs, and satisfaction with a response to needs among mothers. This finding supports the idea that the needs and priorities of each mother are especial for her; hence, it should be taken into consideration in providing medical team interventions to meet maternal needs ((19)). These findings indicate that a mother-to-mother or professional-to-mother support program can be effective in fulfilling these needs. Many mothers are uncomfortable in public settings; then oneby-one support can be helpful in adapting to the experience of having a premature baby.

The present study could attract the mothers' attention to receive maximum support according to the applied aspects such as the daily presence of the professional peer in the hospital, the available phone contact, and the use of a social group of M mothers in social media. Early intervention programs, which focused on increasing the maternal-infant interaction, were other supportive aspects in the present study.

In a meta-analysis by the researcher, the instrumental support was in the highest position both in ranking the importance of fields and ranking the amount of reception ((11)). Consistent with the above result, the instrumental support was the highest perceived support in the present study. The thought that the baby is cared 
by skillful health provider helps to reduce maternal distress ((20)) however, the present study could attract maternal attention to receive maximum support that was not similar to other studies. The highest level of perceived support in the field of instrumental support was due to the fact that the medical staff training was more focused on medical procedures; and doing medical procedures and working with modern equipment was the NICU staff's priority, and communication with mothers was in the next priorities $((9))$.

In the meta-analysis, the informational support was in the second rank of importance and the amount of perceived support. Even though the rates in both Iran and other countries indicated moderate support $((9,11))$, the present study could attract maternal attention to receive maximum support.

In the NICU, women struggle with the frustration of a changed maternal path, and claiming to be a mother has a difficult evolutionary process. Mothers in the NICU are different in terms of the type of emotional exposure to the issue of having a premature baby; hence, the time and nature of supporting them should be designed and implemented individually ((21)).

In the meta-analysis, emotional support was the third field of support that mothers sought, while it was at the lowest level in terms of reception $((8,11))$ and the highest gap was between maternal perception of the importance and perceived reality of support. However, the present study could affect the mothers' adaptation to the infant's disease and other affected aspects of their lives and attract maternal attention to receive maximum support that could not be found in other studies. Since nurses may not have enough time to fulfill maternal emotional needs, involving members of other teams, including social workers and volunteer support groups, can be helpful ((22)). The health team can expand the scope of maternal support by referring mothers to other mothers who have had similar experiences. The program was implemented by Taheri et al. who reported that the unique empirical knowledge provided by experienced mothers in the group was an opportunity to mutual sharing of experiences, create a support system that also extended to mothers until after discharge. In such an environment, the mother receives approval, justification, and empathy from other mothers and becomes aware of how other mothers manage the stress of facing her current situation ((23)). The groups help reduce maternal stress, and learn the effective adaptation $(4,20)$. Iris et al. believed that dialogue and providing a place and time for questions and answers between experienced and inexperienced mothers could lead to effective assimilation and education ((24)).

Receiving support from others (professionals, peer group) improves maternal self-confidence in the ability to care for their infants ((23)). The appraisal support was the lowest field of receiving support in Valizadeh's study in Iran ((17)). In the meta-analysis, receiving the appraisal support from mothers was considered to be moderate, while the present study could be effective in strengthening and supporting the maternal role, and empower the mothers to play active roles in caring for the infants ((11)).

If a mother does not realize that she can play an important role, she will refuse to care for her premature baby in the technological environment of the NICU. She will not stay in the NICU, if the unit is not welcoming for her $((5))$; hence, it is essential to support mothers to manage these challenges.

The identity-based performance of medical staff, who can sympathize with mothers and respecting them, and feel committed to informing and involving them in the care of the babies, as well as promoting the technicalmedical capabilities of caregivers and creating a socio-cultural atmosphere, can provide the possibility of

Page $10 / 14$ 
boosting the maternal self-confidence in taking the serious maternal responsibility (25). Consistent with our findings, Kurniawati also showed that the use of peer support in KMC training compared to training by nurses can significantly increase maternal confidence in the implementation of KMC and increasing the infants' weights (4). The clinical trials, qualitative, cross-sectional, and case studies also reported that the peer-support or professional-led support groups could increase maternal self-confidence in maternal skills $((23,26-28))$.

The total average score of NPST is important because it determines the mother's perception of the level of support by the medical staff, but unfortunately, it is reported to be very low in Iran $((7,8,17))$. Fortunately, maternal perception of provision of support was reported very high in the present study that was not similar to the studies abroad (29-32).

\section{Declarations}

\section{Limitation}

In this paper, concerns about contamination was a limitation leading to sampling in two hospitals.

Despite this disadvantage, the intervention was very effective in promoting perceived support in mothers in different dimensions. Moreover, for each outcome the results remained mainly unchanged after adjustment for baseline differences between groups.

\section{Conclusion}

A multi-faceted approach allows the maternal support program to be set up separately and the natural recovery processes can be facilitated. The information, support and early intervention play important roles in the maternal empowerment to cope with her situation.

\section{Suggestions}

In all NICUs, we suggest defining a job position, called maternal peer, who takes the full, broad, and deep responsibility to meet the maternal supportive needs in the light of full familiarity with the supportive boundaries of mothers with premature infants. This maternal peer, who is better to be an experienced physician, midwife, or nurse with a kind and flexible personality, should be able to establish a trusting relationship with mothers to persuade them into accepting any professional support.

Ethics approval and consent to participate: The study protocol was approved by the Ethics Committee of Shahroud University of Medical Sciences, Shahroud, Iran (code: 930/24). Furthermore, informed written consent was obtained from the participants, and the respondents were completely informed of the study purpose and procedures. In addition, they were assured of the confidentiality of information.

All methods were carried out in accordance with relevant guidelines and regulations.

Consent for publication: Not applicable

Availability of data and materials: The datasets used and analysed during the current study are available from the corresponding author on reasonable request. 
Competing interests: The authors declare that they have no competing interests.

Funding: The present article was extracted from the PhD thesis (code: 930/24) and was supported by grant from Student Research Committee of Shahroud University of Medical Sciences.

Authors' contributions: S.S.M, A.K. and R.Ch. and P.M. were involved in study design. S.S.M. and A.Kh. were involved in Data collection and analysis of results. S.S.M., A.K., P.M., R.Ch., S.A.M., A.Kh. were involved in writing the main manuscript text. All authors reviewed the manuscript.

Acknowledgment: We would like to gratefully thank all mothers that accompanied us in this research.

Authors' information: ${ }^{1}$ Nursing Care Research Center (NCRC), Iran University of Medical Sciences/ Department of Midwifery and Reproductive Health, Iran University of Medical Sciences, Tehran, Iran. ${ }^{2}$ Department of Reproductive Health, School of Nursing and Midwifery, Shahroud University of Medical sciences, Shahroud, Iran. ${ }^{3}$ Department of Epidemioligy, School of Health, Shiraz University of Medical Science, Shiraz, Iran. ${ }^{4}$ Center for Health Related Social and Behavioral Sciences Research, Shahroud University of Medical Sciences, Shahroud, Iran. ${ }^{5}$ Department of Psychiatry, Psychiatry and behavioral sciences research center, addiction institute, Mazandaran University of Medical Sciences, Sari, Iran. ${ }^{6}$ Iran University of medical sciences, Tehran, Iran.

\section{References}

1. Yildiz PD, Ayers S, Phillips $L$. The prevalence of posttraumatic stress disorder in pregnancy and after birth: A systematic review and meta-analysis. Journal of affective disorders. 2017;208:634-45.

2. Flacking $\mathrm{R}$, Breili $\mathrm{C}$, Eriksson M. Facilities for presence and provision of support to parents and significant others in neonatal units. Acta Paediatrica. 2019;108(12):2186-91.

3. Unesi Z, Nakhaee S, Nasirizade M, Izad Panah A. Evaluation of the Relationship Between Perceived Nursing Support and Parental Stress Among Mothers of Hospitalized Preterm Infants in Neonatal Intensive Care Units. Modern Care Journal. 2017;14(4).

4. Kurniawati, Rustina Y, Budiati T. Peer Support Increases Maternal Confidence, Kangaroo Mother Care Implementation and Weight Gain in LBW Infants. Comprehensive child and adolescent nursing. 2019;42(sup1):252-60.

5. Treyvaud K, Spittle A, Anderson PJ, O'Brien K. A multilayered approach is needed in the NICU to support parents after the preterm birth of their infant. Early Human Development. 2019;139:104838.

6. Davidson JE, Aslakson RA, Long AC, Puntillo KA, Kross EK, Hart J, et al. Guidelines for family-centered care in the neonatal, pediatric, and adult ICU. Critical care medicine. 2017;45(1):103-28.

7. Zavalgard E, KhazemNejad Leili E, Jafari AsI M, Shafipour SZ. Viewpoint of Mothers of Premature Newborns about Nursing Supports in Neonatal Intensive Care Units. Journal of Holistic Nursing And Midwifery. 2017;27(1):61-7.

8. Almasi S, Cheraghi F, Roshanaei G, Khalili A, Dehghani M. Relation of Nursing Support From Parents With Meeting the Needs of Mothers of Children Hospitalized in Besat Hospital, Hamadan. Avicenna Journal of Nursing and Midwifery Care. 2018;26(5):323-32. 
9. Aftyka A, Rozalska-Walaszek I, Wrobel A, Bednarek A, Dąbek K, Zarzycka D. Support provided by nurses to parents of hospitalized children-cultural adaptation and validation of Nurse Parent Support Tool and initial research results. Scandinavian journal of caring sciences. 2017;31(4):1012-21.

10. Bekmaz K, Hojjati H, Akhoundzadeh G. Relationship Between Mothers' Concerns and Nursing Support of Children Admitted to Baqiyatallah Al-Azam Hospital of Ali Abad Katoul, Golestan Province, Iran, in 2018. Modern Care Journal. 2019;16(4).

11. Mousavi SS, Chaman R, Khosravi A, Mohagheghi P, Mousavi SA, Keramat A. The needs of parents of preterm infants in Iran and a comparison with those in other countries: a systematic review and metaanalysis. Iranian Journal of Pediatrics. 2016;26(5).

12. Hynan M, Hall S. Psychosocial program standards for NICU parents. Journal of Perinatology. 2015;35(Suppl 1):S1.

13. Mousavi SS, Keramat A, Mohagheghi P, Mousavi SA, Motaghi Z, Khosravi A, et al. The need for support and not distress evoking: A meta-synthesis of experiences of iranian parents with premature infants. Iranian Journal of Psychiatry and Behavioral Sciences. 2017;11(4).

14. Mousavi SS, Chaman R, Mohagheghi P, Mousavi SA, Khosravi A, Keramat A. Development of a support system for parents of premature infants. Iranian Journal of Pediatrics. 2017;27(6).

15. Preyde M, Ardal F. Effectiveness of a parent "buddy" program for mothers of very preterm infants in a neonatal intensive care unit. Canadian Medical Association journal. 2003;168(8):969-73.

16. Miles MS, Carlson J, Brunssen S. The nurse parent support tool. Journal of Pediatric Nursing. 1999;14(1):44-50.

17. Valizadeh L, Zamanzadeh V, Akbarbegloo M, Sayadi L. Importance and availability of nursing support for mothers in NICU: a comparison of opinions of Iranian mothers and nurses. Iranian Journal of pediatrics. 2012;22(2):191.

18. Mansournia MA, Altman DG. Inverse probability weighting. Bmj. 2016;352:i189.

19. Govindaswamy P, Laing S, Waters D, Walker K, Spence K, Badawi N. Needs of parents in a surgical neonatal intensive care unit. Journal of Paediatrics and Child Health. 2019;55(5):567-73.

20. Bastani F, Abadi TA, Haghani H. Effect of family-centered care on improving parental satisfaction and reducing readmission among premature infants: a randomized controlled trial. Journal of clinical and diagnostic research: JCDR. 2015;9(1):SC04.

21. Fowler C, Green J, Elliott D, Petty J, Whiting L. The forgotten mothers of extremely preterm babies: a qualitative study. Journal of clinical nursing. 2019;28(11-12):2124-34.

22. Galanis P, Bilali A, Pouliou K, Matziou V. Factors associated with parents' satisfaction with care provided in a neonatal intensive care unit in Greece. Journal of Neonatal Nursing. 2016;22(4):177-84.

23. Taheri M, Nikfarid L, Farahani AS, Shakeri N. The Effect of a Peer-Group Support Intervention Program on the Tensions of Mothers with Premature Neonates Admitted to the Intensive Care Units in Babol, Iran. Advances in Nursing \& Midwifery. 2018;28(1):15-9.

24. Chertok IRA, McCrone S, Parker D, Leslie N, Catlin A. Review of interventions to reduce stress among mothers of infants in the NICU. Advances in Neonatal Care. 2014;14(1):30-7. 
25. Ghadery-Sefat A, Abdeyazdan Z, Badiee Z, Zargham-Boroujeni A. Relationship between parent-infant attachment and parental satisfaction with supportive nursing care. Iranian journal of nursing and midwifery research. 2016;21(1):71.

26. Brett J, Staniszewska S, Newburn M, Jones N, Taylor L. A systematic mapping review of effective interventions for communicating with, supporting and providing information to parents of preterm infants. BMJ open. 2011;1(1).

27. Rossman B, Greene MM, Meier PP. The role of peer support in the development of maternal identity for "NICU moms". Journal of Obstetric, Gynecologic \& Neonatal Nursing. 2015;44(1):3-16.

28. Hall S, Ryan D, Beatty J, Grubbs L. Recommendations for peer-to-peer support for NICU parents. Journal of Perinatology. 2015;35(1):S9-S13.

29. Tran C, Medhurst A, O'Connell B. Support needs of parents of sick and/or preterm infants admitted to a neonatal unit. NEONATAL, PAEDIATRIC, \& CHILD HEALTH NURSING. 2009;12(2):12-7.

30. Montirosso R, Provenzi L, Calciolari G, Borgatti R. Measuring maternal stress and perceived support in 25 Italian NICUs. Acta paediatrica (Oslo, Norway : 1992). 2012;101(2):136-42.

31. Akbarbegloo M, Valizadeh L, Zamanzadeh V. Comparison of mothers and nurses opinions on quality of nursing care provided to parents with hospitalized premature newborn in NICU. Research Journal of Medical Sciences. 2012;6(4):222-5.

32. Franck LS, Axelin A. Differences in parents', nurses' and physicians' views of NICU parent support. Acta Paediatrica, International Journal of Paediatrics. 2013;102(6):590-6. 